\title{
Therapeutic Plasma Exchange - A 2 Years Experience at a Tertiary Care Centre in Mumbai, Maharashtra, India
}

\author{
Moni Mukesh Udani ${ }^{1}$, Akanksha Jivrag Neogi ${ }^{2}$, Shweta Wasudeo Dhote ${ }^{3}$, Iqbal Singh ${ }^{4}$ \\ 1,2,3,4 Department of Immunohaematology and Blood Transfusion, MGM Medical College and Hospital, \\ Kamothe, Navi Mumbai, Maharashtra, India.
}

\section{ABSTRACT}

\section{BACKGROUND}

Therapeutic plasma exchange is a process where the blood collected from patient is passed through an apheresis instrument where the plasma is removed and discarded and reinfusion of blood cells done with replacement fluids like plasma or albumin to the patient. ${ }^{1}$ It is to remove pathogenic autoantibodies, immune complexes, cryoglobulins and toxins present in the plasma. Plasma exchange is considered effective and cheaper immunomodulatory treatment when compared to intravenous immunoglobulin (IVIG). ${ }^{2}$ We present our institutional experience with therapeutic plasma exchange (TPE) in treatment of various non-neurological and neurological diseases. Our study was conducted to assess the indications, complications and outcome of TPE in the treatment of patients.

\section{METHODS}

A retrospective study of TPE procedures was carried out in the Department of Immunohaematology and blood transfusion, M.G.M Medical College and Hospital, Navi Mumbai from June 2018 to June 2020. A total of 45 procedures were performed among 13 patients between 4 years of age to 66 years of age. Clinical parameters were checked, and laboratory investigations were done before the procedure. Data was collected from the requisition forms by the clinicians and the apheresis database.

\section{RESULTS}

A total of 47 procedures were carried out among 13 patients. TPE is a safe and effective procedure for treating patients with neurologic and non-neurological diseases. Most common indication was Guillain Barre syndrome followed by myasthenia gravis. Incidence of adverse reactions was $7.6 \%$.

\section{CONCLUSIONS}

TPE is a safe and effective procedure for treating patients with neurologic and nonneurological diseases. It benefited 10 out of 13 patients, and they showed complete recovery.

\section{KEY WORDS}

Therapeutic Plasma Exchange, Guillain Barre syndrome
Corresponding Author: Dr. Moni Mukesh Udani, 501, Prince Palace, Near Prashant Corner, Panchpakhadi-400602, Thane West, Maharashtra, India. E-mail: moni.udani42@gmail.com

DOI: $10.14260 /$ jemds/2021/228

How to Cite This Article: Udani MM, Neogi AJ, Dhote SW, et al. Therapeutic plasma exchange - a 2 years experience at a tertiary care centre in Mumbai, Maharashtra, India. J Evolution Med Dent Sci 2021;10(15):1069-1073, DOI: 10.14260/jemds/2021/228

Submission 24-11-2020,

Peer Review 16-02-2021,

Acceptance 22-02-2021,

Published 12-04-2021.

Copyright (C) 2021 Moni Mukesh Udani et al. This is an open access article distributed under Creative Commons Attribution License [Attribution 4.0 International (CC BY 4.0)] 


\section{BACKGROUND}

Therapeutic plasma exchange (TPE) is an extracorporeal (outside the body) blood purification procedure discovered more than a hundred years ago. ${ }^{1}$ It includes removal of pathogenic substances like lipoproteins, auto-antibodies and immune complexes circulating from the plasma ${ }^{2}$ and plays an important role in the management of several diseases.

It is a process in which the patient's blood is processed through apheresis machine, where the plasma is removed and discarded with reinfusion of red blood cells and replacement of fluids such as fresh frozen plasma or albumin to the patient depending upon the requirements. TPE was first implemented in the year 1952 in multiple myeloma to treat hyperviscosity and its varied outcomes. The implied method of blood purification involves removal of high molecular weight proteins from a blood volume passing through membrane plasma separator. ${ }^{3}$ The patient blood is collected into the circuit, separating the plasma from the cellular component which is retained. The diseased plasma is discarded and replenished with replacement fluids. ${ }^{3}$

Plasmapheresis techniques - There are two fundamentally different techniques used for performing plasmapheresiscentrifugation or filtration. ${ }^{4}$ In centrifugation apheresis, whole blood is separated into four blood components depending on their different densities. The whole blood passes through a filter to separate the plasma components from the larger cellular components of red blood cells, white blood cells and platelets in filtration apheresis. ${ }^{5}$ Dr José A. Grifols Lucas introduced therapeutic plasma exchange in 1950 - 1951. Schwab and Fahey in the year 1960 performed the first therapeutic plasma exchange to decrease elevated globulin level in a macroglobulinemia patient. ${ }^{3}$ TPE is normally restricted to 1 or 1.5 plasma volumes.

The basic aim of this treatment is to limit and try reversal of the pathological process mediated by the offending substance causing the disease. ${ }^{6}$ The disadvantage is that it requires a clinician and transfusion medicine physician consultation to agree to carry out the procedure. Filtration plasma exchange is normally advised and done by specialties like nephrology and intensive care units. Continuous venovenous haemodialysis and filtration apheresis can be carried out simultaneously, improving the patient care. The size of the molecules removed corresponds to the filter type which varies on the basis of pore size. ${ }^{7}$

TPE is a rational therapy for diseases where the pathogenesis may be linked to toxic biologic substances that may have relatively higher molecular mass $>15000$ D. ${ }^{8}$ The period between 1963 and 1968 was crucial for [U.S.] National Cancer Institute as the modern plasmapheresis came into existence.

The TPE comprises of five main steps. The steps are as follows -

- Installation of the kit.

- Priming.

- Separation.

- Reinfusion.

- Removal of the apheresis kit.

The advantage of using fresh frozen plasma as an exchange fluid in TPE is that it can also replace missing plasma components, e.g. a disintegrin and metalloproteinase with a thrombospondin type 1 motif, member 13 (ADAMTS13) in TTP. TPE is used in the intensive care setting for e.g. sepsis with multi organ failure or hypertriglyceridemia induced pancreatitis $^{8,9}$ as it removes a plethora of pro-inflammatory cytokines despite lack of data. ${ }^{4}$

\section{Procedure of TPE}

Therapeutic plasma exchange is based on the following Criteria

- A pathogenic substance present in the blood that causes disease or its symptoms.

- That substance can be removed by TPE than by body's mechanisms. ${ }^{10}$

During the procedure, pre-calculated quantity of plasma is removed and replenished with prescribed replacement fluids (fresh frozen plasma or albumin).

The factors affecting the response of TPE in the patient depends on the plasma volume (PV) removed, the patient's total blood and plasma volume.11 The volume of plasma exchange depends on the plasma volume of the patient. After one plasma volume exchange, the material to be discarded will be $35 \%$ of the initial value and one more exchange would further decrease to $15 \%$. It is advised to perform TPE for the optimum time period and volume to assess the potential drug removal of therapies like various immune modulating agents so that proper infection prevention and control measures are followed.

Therapeutic plasma exchange has a definite role in the treatment of patients with Guillain Barre syndrome (GBS), chronic inflammatory demyelinating polyradiculoneuropathy (CIDP), poly neuropathies and myasthenia gravis. ${ }^{12}$ TPE procedure withdraws between 60 to $150 \mathrm{ml} /$ minute permitting to process one plasma volume in almost about 2 to 3 hours. ${ }^{13}$ Proper and adequate venous access for TPE is mostly peripheral or central venous catheter, patency of the veins is important for uneventful procedure. ${ }^{14}$ The American Society for Apheresis elaborated and discussed categories of indications for therapeutic apheresis. ${ }^{9}$ Main complications associated with TPE are bleeding, thrombosis, hypotension, infections, mild arrhythmias and hypersensitivity catheterrelated infections. 15

\section{Objectives}

- To study the role of TPE in the treatment of neurological and non-neurological diseases.

- To observe the experience related to the indication, complication and ultimate outcome of TPE.

\section{METHODS}

This retrospective study was conducted at Department of Transfusion Medicine (blood bank) of a tertiary care hospital, located in Kamothe, Navi Mumbai, India, for a period of two years i.e., from June 2018 to June 2020. All the patients indicated for TPE by the physician admitted in our hospital were included in the study. Proper clinical and laboratory investigations like patient's blood counts, electrolytes, serum proteins, coagulation profile and vitals were analysed and 
steps were taken. The consent was taken from the patient or relative and was attached in the documents.

TPE was performed using a double lumen haemodialysis catheter by central or femoral venous access with intermittent cell separator. The procedures were mostly scheduled on alternate days for a total interval of 8 to 12 days. The separation was achieved by centrifugation, patients received anticoagulation with citrate which differs in proportion from $1: 12$ to $1: 14$ and replacement of fluids was done depending on the volume, time and type of the replacement fluids for every patient. Prophylactic intravenous (IV) calcium gluconate was a part of the protocol. Plasma exchanges were performed with $5 \%$ albumin, fresh frozen plasma, $5 \%$ albumin combined solution and FFP (on an average 5 - 6 units were used) according to the clinicians and intensivists.

The approval to conduct the study was taken by the institutional ethical committee.

\section{Materials Required for TPE}

1. Equipment: FK Comtec Cell Separator

2. PL1 plasma exchange kit.

3. Acid citrate dextrose (anticoagulant).

4. Normal saline $(1000 \mathrm{ml})$, normal saline $(500 \mathrm{ml})$.

5. Replacement fluid - Fresh frozen plasma / albumin (5\%) / normal saline.

6. Sterile gloves, sterile drape, sterile gauze, betadine and spirit.

7. Sterile artery forceps and scissors.

8. Calcium gluconate vial.

9. $10 \mathrm{cc}$ syringe.

10. Emergency tray.

Total 47 procedures were performed among 13 patients. On an average, 1 to 6 cycles were performed per patient. Our study was approved by the institutional ethical committee.

\section{Method of Data Collection}

Systematic recording of the following details were ensured at the time of procedures.

- Indications.

- Number of cycles.

- Volume of exchange and replacement.

- Patient's response to the procedure.

Details of the patient were analysed from the Blood bank records which included apheresis register, apheresis file, requisition forms, patient records and laboratory results. Following data was checked in apheresis and requisition forms.

Our hospital uses the PL1 kit Set for Fresenius Kabi Comtec cell separator.

1. Name, age, sex, height and weight of the patient.

2. Clinical diagnosis.

3. Indication for TPE.

4. Name of the department requesting TPE.

5. No of cycles required.

6. Blood group of the patient.

7. Laboratory investigations of the patient. (Hb, HCT, serum calcium, serum albumin).

\section{Statistical Analysis}

Statistical analysis carried out and P-value and chi-square test were calculated using Microsoft excel and R software 3.6.2. The statistical analysis was done by using chi-square test. The level of significance used was $5 \%$. P-value less than that of 0.05 was considered to be significant. R-software, version 3.6.2 along with Microsoft-Excel is used for statistical analysis purpose.

\section{RESULTS}

\section{Demographic Features}

13 patients underwent TPE during the period from June 2018 to June 2020. A total of 47 sessions were done. It included 8 males and 5 females with maximum cases in the age group between 0 to 75 years. Age group 31 - 40 years had maximum number of cases.

\begin{tabular}{|c|c|}
\hline Diagnosis & No of Patients \\
\hline $\begin{array}{l}\text { Guillain-Barre syndrome } \\
\text { (Category I) }\end{array}$ & $05(39 \%)$ \\
\hline $\begin{array}{l}\text { Myasthenia gravis } \\
\text { (Category I) }\end{array}$ & $03(23 \%)$ \\
\hline $\begin{array}{l}\text { Immunological disorders } \\
\text { (Category I) }\end{array}$ & $02(15 \%)$ \\
\hline $\begin{array}{l}\text { Rapidly progressive glomerulonephritis } \\
\text { (Category I) }\end{array}$ & $02(15 \%)$ \\
\hline $\begin{array}{l}\text { Multiple organ dysfunction syndrome } \\
\text { (Category III) }\end{array}$ & $01(8 \%)$ \\
\hline \multicolumn{2}{|c|}{ Table 1. Indications for TPE } \\
\hline
\end{tabular}

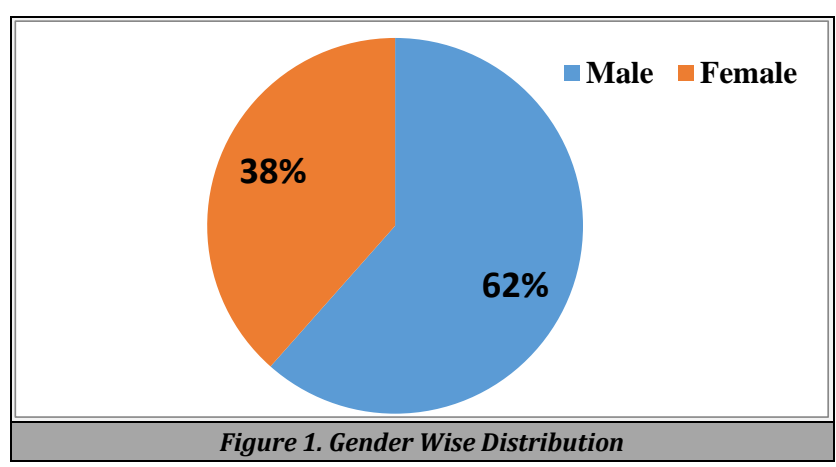

\begin{tabular}{|cc|}
\hline Age & No of Patients \\
$0-10$ & 1 \\
$11-20$ & 1 \\
$21-30$ & 1 \\
$31-40$ & 4 \\
$41-50$ & 2 \\
$51-60$ & 1 \\
$61-70$ & 3 \\
Table 2. Age Wise Distribution & \\
\hline
\end{tabular}

\begin{tabular}{|c|cc|}
\hline & Count & Percentage \\
\hline Complete recovery & 10 & 76.9231 \\
Death & 3 & 23.0769 \\
& Basic Data Distribution \\
Chi-square & Value & P-Value \\
\hline \multicolumn{3}{|c|}{ Table 3. Chi-Square Test Results } \\
\hline \multicolumn{2}{|c}{} \\
\hline
\end{tabular}

\section{Indications of TPE}

The most common indication for TPE in our hospital was Guillain Barre syndrome (39\%) which was followed by 
myasthenia gravis (23 \%). The other indications were immunological disorders ${ }^{5}(15 \%)$, rapidly progressing glomerulonephritis (15\%) and multiple organ dysfunction syndrome (8\%).

\section{Requesting Departments}

Most of the cases were from the medicine department (92\%) followed by paediatrics department (8\%).

\section{Outcome of TPE}

There was complete recovery in $77 \%$ (10) cases whereas 23 $\%(03)$ resulted in death due to other complications and not TPE.

\section{Complications of TPE}

Hypocalcemia and twitching were the most common complication (67\%) followed by hypotension (23\%).

\section{DISCUSSION}

In our study, we assessed the role of therapeutic plasma exchange as a treatment modality for non-neurologic diseases and neurologic diseases. A total of 47 cycles were carried out for 13 patients, and out of 13 patients, 10 (76.92\%) benefited with therapy. 3 of $13(23.07 \%)$ patients experienced adverse reactions, 2 patients experienced hypocalcaemia \& twitching and 1 patient experienced hypotension.

GBS was found to be the main indication in our study that had 13 patients accounting to $39 \%$. Both TPE and IVIG were advisable treatment options in GBS, as they were equally effective and better than the conservative approach.

Ghonemy et al. conducted a prospective study for a period of one year. 276 TPE were carried out for 57 patients of which 49 showed improvement, 2 showed no improvement and 6 deaths. The most common indications were GBS, myasthenia gravis followed by immunological disorders. The most common complications were hypotension and allergic reactions.

In the study by $\mathrm{S}$. Bobati et al. a retrospective study was carried out for a period of 9 years where in 584 TPE were carried out for 161 patients of which 115 showed excellent improvement, 46 showed moderate improvement and no death. The most common indications were GBS, myasthenia gravis, haemolytic-uremic syndrome (HUS) followed by thrombotic thrombocytopenic purpura (TTP) and CIDP. The most common complications were hypotension, inadequate vascular access, chills and rigors. 16

In the study by Joyutpalet al. a retrospective study was carried out for a period of 3 years where in 349 TPE were carried out for 63 patients of which 49 showed improvement and 14 deaths. The most common indications were GBS, myasthenia gravis, CIDP followed by multiple sclerosis.

The American Society for Apheresis has discussed and enumerated the absolute categories of indications for the therapeutic apheresis. The indications of American Society for Apheresis (ASFA) are Category I: Treatment by apheresis is a first line modality, Category II: Treatment by apheresis is a second line therapy when first line failed or are not tolerated,
Category III: There is no proven benefit due to insufficient data, Category IV: Where therapy seems to be harmful. ${ }^{17}$

\begin{tabular}{|c|c|c|c|c|}
\hline \multirow[t]{2}{*}{ Studies } & \multirow[t]{2}{*}{$\begin{array}{l}\text { Number of } \\
\text { Cases Showed } \\
\text { Improvement } \\
\text { (Percentage) }\end{array}$} & \multirow[t]{2}{*}{$\begin{array}{l}\text { Total } \\
\text { Cases }\end{array}$} & \multicolumn{2}{|c|}{$\begin{array}{c}\text { Comparison of Proportion } \\
\text { of Improvement against } \\
\text { Present Study** }\end{array}$} \\
\hline & & & $\begin{array}{l}\text { Chi-Square } \\
\text { Test Value* }\end{array}$ & P-Value \\
\hline Ghonemy et.al. & $49(85.96)$ & 57 & 0.644 & 0.4224 \\
\hline Shreedevi et.al. & $115(71.43)$ & 161 & 0.178 & 0.6729 \\
\hline Joyutpal et.al. & $49(77.78)$ & 63 & 0.005 & 0.9463 \\
\hline Present study** & $10(76.92)$ & 13 & Not Applicable & Not Applicable \\
\hline \multicolumn{5}{|c|}{ Table 4. Comparison of Observed Proportion against Different Studies } \\
\hline \multicolumn{5}{|c|}{ *test of two proportion } \\
\hline
\end{tabular}

Indications of Therapeutic Plasma Exchange The most common indication for TPE in our hospital was Guillain Barre syndrome (39\%) which was followed by myasthenia gravis (23\%). The other indications were immunological disorders (15\%), rapidly progressing glomerulonephritis (15\%) and multiple organ dysfunction syndrome $(8 \%) .{ }^{18,19}$

\section{CONCLUSIONS}

A total of 47 procedures were carried out for 13 patients. TPE is a safe and effective procedure for treating patients with neurologic and non-neurological diseases. It benefited 10 out of 13 patients (76.92\%), it was found that the most common indication in our tertiary care centre was Guillain Barre syndrome followed by myasthenia gravis. According to our assessment, TPE is advised to be utilised earlier in critically ill patients (within 7 to 14 days of onset of illness).

Data sharing statement provided by the authors is available with the full text of this article at jemds.com.

Financial or other competing interests: None.

Disclosure forms provided by the authors are available with the full text of this article at jemds.com.

\section{REFERENCES}

[1] Abel JJ, Rowntree LG, Turner BB. Plasma removal with return of corpuscles (plasmaphaeresis). The Journal of Pharmacology and Experimental Therapeutics Vol. V. No. 6, July, 1914. Transfus Sci 1990;11(2):166-77.

[2] Okafor C, Ward DM, Mokrzycki MH, et al. Introduction and overview of therapeutic apheresis. J Clin Apher 2010;25(5):240-9.

[3] Ghonemy TA, Salim EM, Alsayed SF, et al. Outcomes of therapeutic plasma exchnage; one year single center experience. Urol Nephrol Open Access J 2016;3(5):00096.

[4] Schmidt JJ, Jahn J, Golla P, et al. Effect of therapeutic plasma exchange on plasma levels and total removal of adipokines and inflammatory markers. BMC Obes 2015;2:37.

[5] Williams ME, Balogun RA. Principles of separation: indications and therapeutic targets for plasma exchange. Clin J Am Soc Nephrol 2014;9(1):181-90. 
[6] Wang JMG, Montgomery RA, Kucirka LM, et al. Incompatible live-donor kidney transplantation in the United States: results of a national survey. Clin J Am Soc Nephrol 2011;6(8):2041-6.

[7] Nguyen TC, Kiss JE, Goldman JR, et al. The role of plasmapheresis in critical illness. Crit Care Clin 2012;28(3):453-68.

[8] Eden G, Gradaus F, Brown K, et al. Therapeutic plasma exchange for the treatment of hypertriglyceridemiainduced pancreatitis: a case report. Med Klin Intensivmed Notfmed 2017;112(5):471-4.

[9] Hadem J, Hafer C, Schneider AS, et al. Therapeutic plasma exchange as rescue therapy in severe sepsis and septic shock: retrospective observational single-centre study of 23 patients. BMC Anesthesiol 2014;14:24.

[10] Harmening DM. Modern blood banking and transfusion practices. $6^{\text {th }}$ edn. India: F A Devis 2012.

[11] Simon TL, McCullough J, Snyder EL, et al. Rossi's principles of transfusion medicine. $5^{\text {th }}$ edn. United Kingdom: Wiley-Blackwell 2016.

[12] Schwartz J, Padmanabhan A, Aqui N, et al. Guidelines on the use of therapeutic apheresis in clinical practiceevidence-based approach from the writing Committee of the American Society for Apheresis: the seventh special issue. J Clin Apher 2016;31(3):149-62.

[13] Kielstein JT, Beutel G, Fleig S, et al. Best supportive care and therapeutic plasma exchange with or without eculizumab in Shiga-Toxin-Producing E. Coli 0104: H4 induced haemolytic-uraemic syndrome: an analysis of the German STEC-HUS registry. Nephrol Dial Transplant 2012;27(10):3807-15.

[14] Saran RK. Transfusion Medicine Technical Manual. 2nd edn. New Delhi: Directorate General of Health Services 2003:242-3.

[15] Lu J, Zhang L, Xia C, et al. Complications of therapeutic plasma exchange: a retrospective study of 1201 procedures in 435 children. Medicine (Baltimore) 2019;98(50):e18308.

[16] Bobati SS, Naik KR. Therapeutic plasma exchange-an emerging treatment modality in patients with neurologic and non-neurologic diseases. J Clin Diag Res 2017:11(8):EC35-7.

[17] Aguirre-Valencia D, Naranjo-Escobar J, Posso-Osorio I, et al. Therapeutic plasma exchange as management of complicated systemic lupus erythematosus and other autoimmune diseases. Autoimmune Diseases 2019;2019:5350960.

[18] Lockwood CM, Worlledge S, Nicholas A, et al. Reversal of impaired splenic function in patients with nephritis or vasculitis (or both) by plasma exchange. N Engl J Med 1979;300(10):524-30.

[19] Srauss RG, Ciavarella D, Gilcher RO, et al. An overview of current management. J Clin Apher 1993;8(4):189-94. 